\title{
KEEFEKTIFAN TEKNIK MODELING BERBASIS SINEMA EDUKASI UNTUK MENINGKATKAN EFIKASI DIRI AKADEMIK SISWA SMP
}

\author{
Endang Ragil' ${ }^{1}$ Restu Dwi Ariyanto ${ }^{2}$, Vivi Ratnawati ${ }^{3}$, Risaniatin Ningsih ${ }^{4}$, Dias Rendy Valdino ${ }^{5}$ \\ Universitas Nusantara PGRI Kediri \\ endangragil@unpkediri.ac.id ${ }^{1}$, restudwiariyanto@unpkediri.ac,id², vievie_18@yahoo.co.id², \\ risadyne@gmail.com ${ }^{4}$, diaz.rendyv@gmail.com ${ }^{5}$
}

\begin{abstract}
Phenomenon Students with low academic self-efficacy tend to avoid difficult tasks, because the task is considered a threat to him. Students have low aspirations and commitment in achieving the learning goals they set. When faced with difficult tasks, student is busy thinking about the deficiencies that exist in him, the disturbances he faces, and all the results that can be detrimental. When faced with difficult tasks, students with low self-efficacy will reduce their efforts and tend to give up quickly and slow to fix or regain their self-efficacy when experiencing failure. So we need a technique to reduce these rights, one of which is the application of modeling techniques based on cinema of educational. This study aims to determine the effectiveness modeling techniques based on cinema of educational to improve students' academic self-efficacy. This research method uses an experimental research approach with the type of one group pretest-posttest design. The conclusion of the study showed that the Paired Samples Test score was 0.026 $<0.05$. These results can be concluded that modeling techniques based on cinema of educational are effective for increasing the academic self-efficacy of junior high school students.
\end{abstract}

\section{Key Words} modeling technique, cinema of educational, academic self-efficacy

Cara mengutip: Ragil, E., Ariyanto, R.D., Ratnawati, V., Ningsih, R., \& Valdino, D.R. (2019) Penerapan Teknik Modeling Berbasis Sinema Edukasi Untuk Meningkatkan Efikasi Diri Akademik Siswa. Jurnal Nusantara of Research, 6(1) 50-59.

\section{PENDAHULUAN}

Remaja dihadapkan pada serangkaian tugas perkembangan yang harus dicapai agar mampu mengambil keputusan serta pemecahan masalah secara efektif. Untuk mampu mengambil keputusan dan memecahkan masalah secara efektif diperlukan keyakinan diri terhadap potensi yang dimiliki, sebab keyakinan diri akan mempengaruhi individu dalam mengambil keputusan, memecahkan masalah serta bertahan dalam menghadapi tantangan, Semakin tinggi keyakinan diri individu maka semakin terampil individu dalam membuat keputusan dan memecahkan masalah, sebaliknya semakin rendah keyakinan diri individu, semakin sulit individu untuk membuat keputusan dan memecahkan masalah secara efektif.

Keyakinan diri individu terhadap kemampuan dan potensi yang dimiliki disebut dengan self-efficacy. Bandura (Hen \& Goroshit, 2012:2) menjelaskan "Self-efficacy refers to people's judgments of their own capabilities to organize and execute courses of action required to attain designated types of performances", self-efficacy mengacu pada penilaian individu terhadap kemampuan yang dimilikinya untuk mengatur dan menjalankan rencana tindakan yang diperlukan untuk mencapai hasil yang diharapkan. 
Pada kehidupan sehari-hari individu harus membuat keputusan untuk mencoba berbagai tindakan dan bertahan dalam menghadapi kesulitan-kesulitan. Individu yang efikasi dirinya rendah akan cenderung menghindari situasi-situasi yang diyakini melampaui keyakinan kemampuannya, sebaliknya individu yang efikasi dirinya tinggi akan penuh keyakinan mengambil dan melakukan kegiatan yang diperkirakan dapat diatasi. Efikasi diri yang tinggi menyebabkan keterlibatan aktif dalam kegiatan, mendorong perkembangan kompetensi. Sebaliknya, efikasi diri yang rendah mengarahkan individu untuk menghindari lingkungan dan kegiatan, dan memperlambat perkembangan potensi. Efikasi diri akan membantu individu dalam menentukan kegiatan yang akan dilakukan, kemudian merancang urutan kegiatan dan menentukan berapa lama individu bertahan dalam menghadapi rintangan (Gore, 2006:92).

Efikasi diri (ED) merupakan konsep multidimensional gagasan Bandura yang menyatakan tentang keyakinan keberhasilan terhadap tugas-tugas khusus. Dalam dimensi akademik, tugas-tugas khusus tersebut adalah tugas-tugas dalam bidang akademik. Dengan demikian efikasi-diri akademik (EDA) merupakan keyakinan individu bahwa mereka dapat tampil dengan berhasil pada tugas-tugas akademik sesuai tingkatan yang dipilihnya (Ferla, Valcke, \& Cai, 2009). Efikasi diri (ED) merupakan salah satu dari kepribadian Individu, karena itu berkait dengan aspek pemahaman diri. Bimbingan dalam definisi sebagai konstruk pendidikan ternyata berusaha juga melengkapi pengalaman siswa untuk memahami dirinya (Shertzer and Stone, 1981). Bantuan yang diberikan dimaksudkan untuk mengenal kelebihan dan kekurangannya.

Pada siswa SMP ditemukan beberapa fakta lapangan terkait kondisi efikasi diri akademik siswa. Penyebab efikasi diri ditemukan dari perilaku siswa SMP yang menunjukkan kecemasan dalam menerima beban tugas akademik yang terlalu banyak, hingga pada kebiasaan siswa yang suka menunda-nunda mengerjakan tugas, bahkan cenderung sering menghindar dalam menerima tugas, sehingga akibatnya banyak siswa yang tidak tepat waktu menyelesaikan dan mengumpulkan tugas. Hal ini perlu segera ditangani untuk meningkatkan efikasi diri khususnya terkait akademik. Salah satu yang dapat dilakukan oleh guru BK adalah dengan menggunakan teknik modeling. Teknik ini merupakan proses pengamatan terhadap tingkahlaku orang yang dijadikan model.

Teknik modeling mengacu pada proses melalui pengamatan terhadap pola pikir, keyakinan serta perilaku mereka setelah ditampilkan oleh satu atau lebih model (Schunk dalam Schunk \& Zimmerman, 2007). Model akan memberikan informasi mengenai hal-hal yang akan meningkatkan efikasi-diri (ED). Teknik modeling berisi tahap-tahap yang akan lebih maksimal apabila dilaksanakan menggunakan sinema edukasi. Sehingga teknik simbolik modeling sesuai dengan sinema edukasi. Teknik simbolik modeling adalah berupa pemberian treatmen lewat tayangan sinema edukasi. Sinema edukasi yang digunakan dalam penelitian ini merupakan beragam film yang diperoleh dari beragam sumber yang disesuaikan dengan kondisi efikasi diri akademik siswa SMP. Tujuan penelitian adalah untuk mengetahui keefektifan teknik modeling berbasis sinema edukasi untuk meningkatkan efikasi diri akademik siswa SMP. 


\section{METODE}

Penelitian ini menggunakan pendekatan penelitian kuantitatif. Desain penelitian menggunakan experiment yaitu pendekatan penelitian yang menguji apakah variabel independent dapat mempengaruhi variabel dependent (Cresswell, 2012). Menurut Cohen (2007), penelitian experiment adalah penelitian yang didalamnya terdapat suatu intervensi dan pengukuran sebelum dan setelah diberikan intervensi. Secara khusus teknik experiment yang digunakan dalam penelitian ini adalah pre-experiment dengan jenis one group pretestposttest design. Pre-experiment belum merupakan eksperimen sungguh-sungguh karena terdapat variabel lain yang ikut berpengaruh terhadap terbentuknya variabel dependent (Sugiyono, 2012). Adapun gambar design dapat dilihat sebagai berikut.

\begin{tabular}{|lll|}
\hline $\mathrm{O}_{1}$ & $\mathrm{X}$ & $\mathrm{O}_{2}$ \\
\hline
\end{tabular}

Gambar 3.1 one group pretest-posttest design (Sugiyono, 2012)

Adapun tahap-tahap dalam penelitian ini adalah tahap pertama pelaksanaan pretest, tahap kedua pelaksanaan treatment, dan tahap ketiga pelaksanaan posttest. Sampel penelitian menggunakan purposive sampling sejumlah 10 siswa yang mengalami efikasi diri akademik rendah. Prosedur pengumpulan data melalui Pedoman Observasi, Pedoman Wawancara dan Skala Pengukuran Efikasi Diri Akademik Siswa. Analisis data menggunakan uji Paired Sample T-test dengan bantuan program SPSS IBM Statistic 24.0. Pengujian ini menggunakan ketentuan sebagai berikut: 1) apabila signifikansi > 0,05 maka Ho diterima dan 2) apabila signifikansi $<0,05$ maka Ha ditolak. Data-data yang bersifat non angka/verbal yakni berupa pendapat siswa akan dideskripsikan dan digunakan sebagai bahan pendukung. Bahan pendukung untuk menarik kesimpulan dari deskripsi tersebut, sehingga memberikan gambaran yang jelas terhadap aspek yang dinilai. Populasi kelas VIII SMP 4 Kediri sejumlah 343 siswa. Sampel penelitian diambil dengan teknik purposive sampling sejumlah 10 siswa dengan kriteria mengalami efikasi diri yang rendah dan hasil rekomendasi dari guru BK di Sekolah.

\section{HASIL}

Berdasarkan hasil penelitian, berikut akan dibahas hasil temuan tersebut secara lebih jelas. Tahap pertama saat pelaksanaan pretest kepada sepuluh siswa di SMPN 4 Kediri kondisi awal masih tergolong rendah, siswa masih memiliki efikasi diri akademik yang kurang. Kemudian dilakukan proses posttest dengan memberikan materi berupa sinema edukasi yang telah disesuaikan dengan indikator efikasi akademik siswa. Data menunjukkan bahwa hasil pretest dan posttest mengalami peningkatan efikasi diri akademik. Secara lebih detail hal tersebut dapat dilihat pada tabel 1.1.

Berdasarkan hasil tabel 1.1 maka dapat ditarik kesimpulan bahwa ada peningkatan pemahaman efikasi diri akdemik siswa melalui tayangan sinema edukasi. Mayoritas siswa menunjukkna tren skor naik artinya dengan mennggunakan media sinema edukasi mampu membuat stimulus mereka mengalamai peningkatan dalam memahami efikasi akadaemik. 
Tabel 1.1. Hasil Pretest dan Posttest

\begin{tabular}{ccc}
\hline $\begin{array}{c}\text { Nama } \\
\text { Siswa }\end{array}$ & Skor Pretest & Skor Posttest \\
\hline CNS & 124 & 129 \\
\hline RAA & 123 & 116 \\
\hline MZM & 125 & 138 \\
\hline AZA & 128 & 145 \\
\hline RSB & 129 & 135 \\
\hline VK & 116 & 129 \\
\hline LS & 132 & 132 \\
\hline RCQ & 119 & 138 \\
\hline IWB & 133 & 134 \\
\hline MRF & 128 & 131 \\
\hline
\end{tabular}

Proses analisis uji hipotesis diperlukan beberapa syarat langkah statistik yang harus dilakukan setiap tahapan. Dalam trangka untuk mengetahui uji hipoteisis terkait penerapan teknik modeling berbasis sinema edukasi untuk meningkatkan efikasi diri akademik siswa di SMPN 4 Kediri maka perlu dilakukan uji stsitistik dengan berbantuan SPSS 24.0. Langkah pertama adalah melakukan uji homogenitas untuk mengetahui data tersebut homogen atau tidak. Selanjutnya diperlukan uji normalitas agar diketahui data penelitian berdistribusi normal. Setelah data homogen dan berdistribusi normal kemudian dilakukan uji Paired Samples Test untuk mengethaui apakah terdapat perbedaan rata-rata dua sampel (dua kelompok) yang saling berhubungan atau berpasangan.

Uji homogenitas dengan berbantuan SPSS 24.0 menunjukkan bahwa data penelitian homogen. Artinya variasi beberapa data dari populasi memiliki varians yang sama. Berikut table data hasil uji homogenitas yang telah dianalisis.

Tabel 1.2. Hasil Pretest dan Posttest

\begin{tabular}{rrrrrr}
\hline \multicolumn{5}{c}{ Test of Homogeneity of Variances } \\
\begin{tabular}{rlllll}
\hline PREPOST & \multicolumn{5}{l}{} \\
\hline Levene Statistic & df1 & & df2 & Sig. \\
\hline .279 & & 1 & & 18 & .604 \\
\hline
\end{tabular}
\end{tabular}

Berdasarkan uji homogenitas varian data efikasi diri akademik kelas eksperimen, diperoleh taraf signifikan sebesar 0.279 . Hasil uji homogenitas $0.279>0.05$, maka $\mathrm{H}_{0}$ diterima. Hal ini menunjukkan bahwa data efikasi diri akademik kelas eksperimen mempunyai variansi yang homogen. Maka dapat disimpulkan bahwa varians data hasil penerapan teknik modeling berbasis sinema edukasi untuk meningkatkan efikasi diri akademik adalah homogen.

Setelah melakukan uji homogenitas maka langkah selanjutnya adalah melakukan uji normalitas. Uji Normalitas bertujuan untuk mengetahui apakah variasi beberapa data dari populasi memiliki varians yang sama atau tidak. Uji ini berfungsi sebagai syarat dalam analisis uji independent sampel t tes dan uji anova. Berdasarkan hasil pengolahan SPSS 24 diperoleh data uji normalitas sebagai berikut. 
Ragil, Ariyanto, Ratnawati, Ningsih, Valdino

Keefektifan Teknik Modeling Berbasis Sinema Edukasi untuk Meningkatkan Efikasi Diri...

Tabel 1.3. Hasil Uji Normalitas

\begin{tabular}{llr}
\hline \multicolumn{3}{c}{ One-Sample Kolmogorov-Smirnov Test } \\
\hline $\mathrm{N}$ & \multicolumn{1}{c}{ PREPOST } \\
\hline Normal Parameters $\mathrm{a}, \mathrm{b}$ & Mean \\
\cline { 2 - 3 } & Std. Deviation & 129.20 \\
\hline Most Extreme Differences & Absolute & 7.374 \\
\cline { 2 - 3 } & Positive & .135 \\
\cline { 2 - 3 } & Negative & .067 \\
\hline Test Statistic & -.135 \\
\hline Asymp. Sig. (2-tailed) & .135 \\
\hline a. Test distribution is Normal. & $.200 \mathrm{c}, \mathrm{d}$ \\
\hline b. Calculated from data. & \\
\hline c. Lilliefors Significance Correction. \\
\hline d. This is a lower bound of the true significance. \\
\hline
\end{tabular}

Berdasarkan hasil output "One-Sample Kolmogorov-Smirnov Test" pada tabel diatas, diperoleh nilai Asymp. Sig. (2-tailed) $0.2>0.05$, maka $\mathrm{H}_{0}$ diterima. Hal ini menunjukkan bahwa data efikasi diri akademik kelas eksperimen berasal dari populasi yang berdistribusi normal. Data penelitian menunjukkan normal dan homogen sehingga menggunakan statistik parametrik dengan uji Paired Samples Test. Uji ini bertujuan digunakan untuk mengetahui apakah terdapat perbedaan rata-rata dua sampel (dua kelompok) yang saling berhubungan atau berpasangan. Berdasarkan hasil analisis uji statitistik menggunakan SPSS 24.0 diperoleh data penelitian homogen dan berdistribusi normal. Hal ini menandakan bahwa diperlukan uji statisitik parametrik dengan uji Paired Samples Test. Berikut adalah gambaran tabulasi data hasil analisis uji Paired Samples Test.

Tabel 1.4. Hasil Uji Paired Samples Test

\begin{tabular}{|c|c|c|c|c|c|c|c|c|c|}
\hline \multicolumn{10}{|c|}{ Paired Samples Test } \\
\hline & & $\begin{array}{l}\text { Paired } \\
\text { Differences }\end{array}$ & & & & & $t$ & df & $\begin{array}{l}\text { Sig. (2- } \\
\text { tailed) }\end{array}$ \\
\hline & & & $\begin{array}{l}\text { Std. } \\
\text { Deviation }\end{array}$ & $\begin{array}{l}\text { Std. Error } \\
\text { Mean }\end{array}$ & $\begin{array}{l}95 \% \\
\text { Confiden } \\
\text { ce } \\
\text { Interval of } \\
\text { the } \\
\text { Differenc } \\
\mathrm{e}\end{array}$ & & & & \\
\hline & POSTES & Mean & & & Lower & Upper & & & \\
\hline $\begin{array}{l}\text { Pair } \\
1\end{array}$ & $\begin{array}{l}\text { T - } \\
\text { PRETEST }\end{array}$ & 7 & 8.287 & 2.62 & 1.072 & 12.928 & 2.671 & 9 & 0.026 \\
\hline
\end{tabular}

Berdasarkan tabel output "Paired Samples Test" pada tabel diatas, diketahui nilai Sig (2 tailed) adalah sebesar $0.026<0.05$, hal ini juga diperkuat oleh hasil nilai t sebesar 2.671, maka Ho ditolak dan Ha diterima. Dari data tersebut dapat disimpulkan bahwa teknik modeling berbasis sinema edukasi efektif untuk meningkatkan efikasi diri akademik siswa SMPN 4 Kediri. 


\section{PEMBAHASAN}

Keefektifan teknik modeling berbantuan sinema edukasi untuk meningkatkan efikasi diri akademik ditunjukkan oleh skor posttest siswa yang mengalami peningkatan dari hasil pretest. Siswa mengalami kemajuan dalam setiap pertemuan dalam kelas eksperimen yang dapat dilihat dalam lembar hasil refleksi. Kondisi awal mereka memiliki tingkat efikasi diri rendah dan akhirnya mengalami peningkatan menjadi tinggi. Kesepuluh siswa yang mengikuti proses treatment memperlihatkan adanya kemauan dan upaya yang signifikan dari masingmasing siswa untuk meningkatkan efikasi diri akademik. Hal tersebut dapat terlihat ketika mengikuti kegiatan treatment dan menunjukkan respon positif meskipun kadang ada satu atau dua siswa yang terlihat tidak fokus pada pertemuan tertentu. Kondisi ini berpengaruh pada kenaikan skor yang kurang signifikan. Siswa mampu memahami isi cerita film, mengambil nilai-nilai positif dari setiap tokoh yang ada dalam film dan mampu mengungkapkan perasaannya baik ketika dihadapkan menjadi seperti karakter tokoh film maupun tindakan ideal apa yang harus dilakukan apabila mengalami konflik seperti di film. Pernyataan tersebut menandakan bahwa teknik modeling berbasis sinema edukasi dapat meningkatkan efikasi diri akademik siswa SMP, sehingga memperkuat hipotesis awal yaitu teknik ini terbukti efektif diterapkan pada siswa.

Sinema yang berfokus pada cerita yang timbul dari pengalaman penting yang sesuai keadaan diri akan menarik perhatian siswa. Menurut studi yang dilakukan Chambers (2019) tentang film dari jenjang sekolah dasar hingga perguruan tinggi, ditemukan bahwa pada tataran usia sekolah menengah siswa lebih menyukai film yang berfokus pada pengalaman pribadi siswa. Mereka akan mudah memahami adegan dramatis yang dimunculkan dalam film. Muatan budaya dalam film juga sangat berpengaruh terhada proses releksi diri siswa (Aidelman, N. \& Colell, L, 2018) dan mempengaruhi degradasi moral yang ditandai oleh kurangnya menghargai norma budaya dan rendahnya pemhaman diri (Njoku, 2016). Artinya sekolah memegang peran penting dalam proses mentransfer nilai-nilai yang akan dimunculkan dalam sebuah sinema edukasi agar mendorong siswa mampu merefleksikan pesan yang terkandung dalam sebuah sinema.

Proses merefleksikan sinema edukasi juga dipengaruhi oleh jenis modeling yang ditampilkan dalam sebuah tayangan. Simbolik modeling efektif dalam memberikan stimulus pada siswa dalam menggali nilai dan pesan yang disampaikan dalam film. Bandura (1977; 2009) menjelaskan bahwa ada tiga macam modeling yaitu model hidup (life-modeling), model instruksional verbal (verbal instructional model), model simbolik (symbolic-modeling). Model simbolik dipilih dalam riset karena menunjukkan bahwa animasi tokoh-tokoh film mampu mendorong siswa lebih aktif meningkatkan keyakinan belajar, mampu meminimalisir rasa takut akan gagal, dan segera bangkit apabila menemui kegagalan dari masalah terutama yang berkaitan dengan akademik. Senada dengan pendapat Cormier dan Cormier (1985), teknik modeling memiliki beberapa unsur yaitu: (1) ada kesamaan sifa-sifat pemakai dengan model yang ditampilkan, (2) tingkahlaku model di spesifikasi, (3) menggunakan media tertulis atau rekaman (audio, video, film, atau slide), (4) ada skrip akan disajikan (instruksi, modeling, latihan, balikan, dan ringkasan), dan (5) testing lapangan dari model yang telah 
dikembangkan. Simbolik modeling juga bisa digunakan untuk meningkatkan efikasi diri akademik siswa.

Modeling dalam sinema edukasi yang ditayangkan pada riset ada dua jenis yaitu berupa film animasi dan film dokumenter figur seseorang. Dari hasil penelitian menunjukkan siswa lebih tertarik dengan film yang berjenis animasi. Menurut Yakar (2018) film animasi memberikan dampak kemenarikan yang tinggi bagi subjek penelitian yakni $24 \%$ dibandingkan jenis film dokumenter $6 \%$. Siswa menunjukkan perhatian yang aktif saat ditayangkan film berjenis animasi karena banyak model tokoh lucu yang menjadi perhatian dibanding film dokumenter yang tokohnya monoton dan membuat jenuh. Temuan lain menunjukkan bahwa dengan adanya model simbolik pada sebuah sinema edukasi akan mendorong siswa untuk lebih aktif berbagi perasaan tentang film. Hal ini senada dengan pendapat (Kresse \& Watland, 2016) bahwa pengaruh film akan mendorong siswa untuk bekolaborasi aktif dalam kelompok terutama proses mengutarakan pendapat terkait adegan yang sudah dilihat. Sehingga proses peningkatan efikasi diri akademik dalam aspek perasaan mampu ditunjukkan dengan siswa tertarik pada bidang studi, rajin mencari informasi tentang bidang studi, dan senang memilih program belajar yang sesuai dengan passion.

Selanjutnya dalam aspek performance dapat ditunjukkan dengan siswa memiliki keyakinan mampu menyelesaikan studi, memiliki rencana pendidikan yang baik, memiliki kemauan yang kuat untuk diri sendiri, mampu menggunakan waktu yang banyak dalam menghadapi tantangan, mampu memiliki banyak ide menyelesaikan masalah, dan peningkatan kecakapan dalam mengganti strategi yang gagal. Dalam aspek persistence diperoleh hasil bahwa siswa memiliki keberanian yang tinggi untuk menerima kegagalan, mampu bangkit kembali setelah menerima kegagalan, dan berusaha mencapai tujuan akedemik yang telah ditetapkan di awal melalui model simbolik dalam sinema edukasi.

Modeling merupakan tingkahlaku yang didemonstrasikan (dipertunjukkan) yang merupakan stimulus untuk belajar (Loucas \& Zacharias, 2012). Teknik menggunakan modeling sebagai sarana untuk memfasilitasi perubahan dapat meningkatkan stimulus siswa dalam belajar. Modeling mengacu pada proses melalui pengamatan terhadap pola pikir, keyakinan serta perilaku mereka setelah ditampilkan oleh satu atau lebih model (Schunk \& Zimmerman, 2007). Dapat disimpulkan bahwa teknik modeling merupakan proses pengamatan terhadap tingkahlaku orang yang dijadikan model, untuk sebagai suatu stimulus untuk belajar.

Aspek lain yang dapat dilihat dari sinema edukasi bahwa siswa akan cenderung menirukan model yang ditayangkan dalam sebuah film baik film animasi maupun dokumenter tentang figur seseorang. Perilaku siswa dalam menirukan model merupakan bagian dari teknik modeling yang dapat digunakan sebagai teknik intervensi untuk mengubah perilaku siswa. Teknik modeling memungkinkan untuk memberikan intervensi pada siswa melalui pemodelan dalam tokoh modeling dalam sinema. Salah satu bukti adalah penelitian yang dikemukakan oleh Meyers dan Craighead (dalam Benyamin, Puleo, Settipani, Brodman, Edmund, Cummings, Kendall, 2011) mengidentifikasikan bahwa kekuatan yang dapat mengintervensi perilaku anak-anak yaitu dengan melalui (a) pemodelan, (b) pelatihan 
pembelajaran diri, dan (c) pemecahan masalah. Dengan demikan siswa akan mampu mencapai target akademik yang dicapai melalui sinema edukasi.

Menurut Yakar (2018) bahwa tujuan yang dapat dicapai dalam menggunakan sinema dalam pembelajaran ada beragam aspek yang mendukung penelitian adalah pecapaian akademik (academic achievment), pengembangan kompetensi sosial (social development), dan pengembangan kompetensi emosi (emotical development). Pencapaian akademik akan berhubungan erat kaitannya dengan efikasi diri akademik siswa. Bandura (1977) menjelaskan bahwa ada tiga dimensi efikasi diri yang dapat menjadi penilaian berhasil atau tidaknya siswa mengelola diri yakni: 1) Magnitude, yang berkaitan dengan tingkat kesulitan tugas, sejauh-mana individu merasa mampu dalam melakukan berbagai tugas dengan sederhana, yang agak sulit, hingga yang sangat sulit; tugas, sejauhmana individu merasa mampu dalam melakukan berbagai tugas dengan tingkat kesulitan tugas, mulai dari yang sederhana, yang agak sulit, hingga yang sangat sulit; 2) Generality, sejauhmana individu yakin akan kemampuannya dalam berbagai situasi tugas, mulai dari dalam melaku-kan suatu aktivitas atau situasi tertentu, hingga dalam serangkaian tugas atau situasi yang bervariasi; 3 ) Strength, kuatnya keyakinan seseorang mengenai kemampuan yang dimiliki.

Lebih lanjut lagi bahwa siswa yang dikatakan memiliki efikasi diri akan memiliki dua konstruk yaitu kepercayaan-diri (efficacy-belief) dan pengharapan-hasil (outcome expectations) dalam dirinya (Bandura, 1986: 391-393; Bell, 1986: 250-251; Elliot et al., 2000: 352). Hasil riset menunjukkan bahwa kepercayaan diri terkait efikasi diri akademik melalui modeling sinema edukasi ditunjukkan oleh sikap yakin mampu menyelesaikan studi, menggunakan waktu yang banyak menghadapi tantangan dan mengganti strategi yang gagal mampu mengakomodasi hasil pencapaian akademik (outcome expectations) yang dilakukan.

\section{KESIMPULAN DAN SARAN}

Kesimpulan hasil penelitian menunjukan bahwa penerapan teknik modeling berbasis sinema edukasi terbukti efektif untuk meningkatkan efikasi diri Siswa SMPN 4 Kediri yang ditunjukkan skor uji Paired Samples Test sebesar 0.026. Berdasarkan hasil penelitian yang telah dilakukan maka disarankan bagi peneliti selanjutnya bahwa (1) perlu diperhatikan durasi sinema yang akan ditayangkan, (2) perlu lebih detail mencermati instrumen penelitian yang sesuai dengan karakterstik siswa agar diperoleh data mendalam tentang kondisi efikasi diri akademik siswa, dan (3) perlu menggunakan metode penyampaian materi yang lebih variatif dan menarik bagi siswa saat memberikan perlakuan (treatment).

\section{DAFTAR RUJUKAN}

Aidelman, N. \& Colell, L.2018. Transmitting cinema: Some Proposals For Our Time. Film Education Journal. 1 (2): 147-162.

Bandura, A. 1977.Social Learning Theory. USA: Prentice-Hall

Bandura, A. (1986). Social Foundations of Thought and Action. Englewood Cliffs, NJ: Prentice Hall.

Bandura, A. 2009. Self Efficacy in Changing Societies. New York: Cambridge University Press. 
Bell,1986. Learning and Instruction, Theory and Practice. New York : Macmillan Publishing Campany.

Benyamin, Courtney L., Puleo, Connor M., Settipani, Cara A., Brodman, Douglas M., Edmund, Juli M., Cummings, Colleen M., Kendall, Philip M., (2011). History of CognitiveBehavioral Therapy (CBT) in Youth. Journal List NIH Public Access. 20 (2): 179-189.

Bernstein, A. \& Burn, A. 2019. Perspectives: A dialogue Upon The Question Of Value In Film Education. Film Education Journal. 2 (1): 71-8.

Chambers, J.2019. Exploring co-creation in practical film education from primary school to postgraduate study: Theoretical and auto-ethnographic perspectives upon teaching film practice. Film Education Journal. 2 (1): 27-47.

Cohen, L., Manion, L., \& Morrison, K. 2007.Research Methods in Education (6thed.). London, New York: Routllege Falmer.

Cormier,W.H.and Cormier, L.S. (1985). Interviewing Strategies for Helpers: Fundamental Skill Cognitive Behavioral Interventions. Monterey, California: Brooks/Cole Publishing Company.

Creswell, J., W., 2012. Research design Pendekatan kualitatif, Kuantitatif dan Mixed; Cetakan ke-2.Yogyakarta: Pustaka Pelajar.

Elliott, Stephen N., Thomas R. Kratochwill, Joan Littlefield Cook, John F. Travers. 2000. Educational Psychology; Effective Teaching, Effective Learning. Third Edition. United States: The Mc Graw Hill Companies, Inc.

Ferla, J,. Valcke, M,. Cai, Y. 2009. Academic self-efficacy and academic self- concept: reconsidering structural relationships. Learning and Individual Differences. 19 (4) 499-505.

Gore, P.A. 2006. Academic self-efficacy as a predictor ofcollege outcomes: Two incremental validity studies. Journal of Career Assessment. 14 (1) 92-115.

Hen, M \& M. Goroshit. 2012. Academic Procrastination, Emotional Intelligence, Academic Self-Efficacy, and GPA: A Comparison Between Students With and Without Learning Disabilities. Journal of Learning of Disabilities. XX (X) 1-9.

Kresse,W., \& Watland, K.H. 2016. Thinking Outside the Box Office: Using Movies to Build Shared Experiences and Student Engagement in Online or Hybrid Learning. Journal of Learning in Higher Education. 12 (1).

Loucas T. L \& Zacharias C. Z. 2012. Modeling-Based Learning In Science Education: Cognitive,Metacognitive, Social, Material And Epistemological Contributions. Educational Review. 64 (4) 471-492.

Njoku, N.C. 2016. Impact of Nigerian Home Video/Movie Industry on the Moral Behaviours of Secondary School Students in Ebony State of Nigeria. Journal of Education and Practice. 7 (26) 182-186. 
Schunk, D. H., \& Zimmerman, B. J. (2007). Influencing Children's Self-Efficacy And SelfRegulation Of Reading And Writing Through Modeling. Reading and Writing Quarterly. 23 (1) 7-25.

Sugiyono. 2012. Metode Penelitian Kuantitatif Kualitatif dan R\&D. Bandung: Alfabeta.

Yakar, H.G. 2018. Use of the Movies in the Turkish Language and Literature Education in Turkey. Journal of Education and Learning. 7 (3) 41-55. 